\title{
CDX2 is involved in microRNA-associated inflammatory carcinogenesis in gastric cancer
}

\author{
MOTONOBU SAITO ${ }^{1,2}$, HIROKAZU OKAYAMA ${ }^{1}$, KATSUHARU SAITO $^{1}$, JIN ANDO $^{1}$, \\ KENSUKE KUMAMOTO $^{1}$, IZUMI NAKAMURA ${ }^{1}$, SHINJI OHKI ${ }^{1}$, \\ YOSHIMASA ISHI $^{3}$ and SEIICHI TAKENOSHITA ${ }^{1}$
}

\begin{abstract}
${ }^{1}$ Department of Organ Regulatory Surgery, Fukushima Medical University School of Medicine, Fukushima 960-1295; ${ }^{2}$ Division of Genome Biology, National Cancer Center Research Institute, Tokyo 104-0045;

${ }^{3}$ Department of Surgery, Ohta Nishinouchi Hospital, 2-5-20 Nishinouchi, Koriyama 963-8558, Japan
\end{abstract}

Received August 18,2015; Accepted June 15, 2017

DOI: $10.3892 / \mathrm{ol} .2017 .6956$

\begin{abstract}
The development of gastric cancer is significantly associated with chronic inflammation, such as caused by Helicobacter pylori (H. pylori) infection. Caudal-type homeobox 2 (CDX2) is a homeobox protein involved in intestinal differentiation in normal and in aberrant locations, and is associated with inflammation. The authors of the present study have previously reported that CDX2 may have a suppressive role in the progression and carcinogenesis of gastric carcinoma. In the present study, the authors initially confirmed that a decreased expression of CDX2, as detected by immunohistochemistry, is associated with poor cancer-specific survival in 210 gastric cancer cases, which is consistent with several previously published studies. To elucidate the potential mechanisms underlying this association, the authors investigated the mechanism of CDX2 suppression, which included interleukin (IL)-6/signal transducer and activator of transcription 3 (STAT3) and p53 signaling pathways. The present study confirmed that CDX2 was suppressed by activation of the IL-6/STAT3 signaling pathway via miR-181b in vitro. It was further revealed that gastric cancer with negative CDX2 expression is associated with negative p53 staining, and this association was particularly significant in undifferentiated gastric cancer. The activation of the IL-6/STAT3 signaling pathway suppressed miR-34a, which is induced by p53. This suggests that the activation of the IL-6/STAT3 signaling pathway inflammation signaling pathway suppresses the p53 signaling pathway in tumors without TP53 mutation, which results in poor prognostic outcomes. In conclusion, CDX2
\end{abstract}

Correspondence to: Professor Seiichi Takenoshita, Department of Organ Regulatory Surgery, Fukushima Medical University School of Medicine, 1 Hikarigaoka, Fukushima 960-1295, Japan

E-mail: takenoss@fmu.ac.jp

Key words: gastric cancer, caudal-type homeobox 2, miR-181b, interleukin-6/signal transducer and activator of transcription 3 pathway, p53 may be a useful prognostic biomarker for gastric cancer and is associated with $\mathrm{p} 53$ inactivation.

\section{Introduction}

Gastric cancer is responsible for $10 \%$ of total mortalities worldwide every year, and the rate of the disease is particularly high in in males and developing countries (1). While the precise underlying tumorigenesis mechanism of gastric cancer has not been fully understood, a number of risk factors have been reported, including a low intake of vegetables, an excess intake of salty food and smoking (2). Another major factor that is associated with the development of gastric cancer is chronic inflammation, which is caused by Helicobacter pylori (H.pylori) infection (3). In addition to $H$, pylori, recent studies have also revealed various intrinsic mediators that are involved in inflammation-associated carcinogenesis (4).

Caudal-type homeobox 2 (CDX2) is a caudal-related homeobox transcription factor, which is involved in intestinal differentiation in normal and in aberrant locations. The authors of the present study and others have previously reported that CDX2 may exert a suppressive role in progression and carcinogenesis of gastric carcinoma $(5,6)$. Consistent with these results, four reports have demonstrated that negative CDX2 expression was associated with poor survival in gastric cancer patients (7-10). However, other studies reveled that CDX2, which is ectopically observed in intestinal metaplasia in the stomach, may increase the risk of gastric cancer development $(11,12)$. Therefore, further studies will be required to elucidate the functional role of CDX2 in inflammation-associated gastric carcinogenesis and investigate the uses of prognostic biomarkers.

MicroRNAs (miRNAs/miRs) are short noncoding RNAs that specifically regulate the translation of target genes (13). Through this function, miRNAs affect a variety of cellular functions, including proliferation, differentiation, and apoptosis and have a causal role in tumorigenesis including inflammation-associated carcinogenesis. Signal transducer and activator of transcription 3 (STAT3) is a downstream of interleukin (IL)-6 and form an inflammatory positive feedback loop with nuclear factor $\kappa \mathrm{B}, \mathrm{Lin} 28 \mathrm{~B}$, miR-181b and 
miR-21 (14). Because CDX2 is one of the targets of miR-181b, the regulation of CDX2 may be involved in the IL-6/STAT3 signaling pathway via miR-181b (15). Furthermore, the IL-6/STAT3 signaling pathway also forms a feedback loop with miR-34a that is induced by p53 (16).

The present study collected 210 patients with gastric cancer and focused exclusively on inflammation-associated carcinogenesis. Based on a previous report by the present authors (5), the present study first confirmed that negative CDX2 expression was associated with cancer-specific survival in patients with gastric cancer. Subsequently, in order to elucidate the functional role of CDX2 suppression in inflammation-associated carcinogenesis, the interactions between the IL-6/STAT3 signaling pathway, miR-181b, miR-34a, and p53 expression were investigated experimentally.

\section{Materials and methods}

Tissue samples. Primary gastric adenocarcinoma specimens were procured from patients undergoing surgical resections. In a total of 210 cases, 78 cases were recruited from Ohta Nishinouchi Hospital (Fukushima, Japan) from January 2001 to December 2003. A total of 132 cases were recruited from Fukushima Medical University (Fukushima, Japan) from January 1991 to December 2004. The cases from Fukushima Medical University were included in a previous study by the authors (5). All patients were Japanese, and no patients received chemotherapy or radiotherapy prior to surgery. Data including age, gender, tumor-node-metastasis (TNM) stage $(17,18)$ and pathological diagnosis, (lymphatic and venous invasion), were retrospectively collected. As with the previous study by the authors (5), the cases were divided into two types, differentiated and undifferentiated. The differentiated type was defined as patients with well and moderately differentiated tubular or papillary adenocarcinomas, and the undifferentiated type included patients with poorly differentiated adenocarcinomas and signet-ring cell carcinomas. The average overall 5-year survival rate was $68.8 \%$. The present study was approved by the Ethics Committee of the Fukushima Medical University. Written informed consent was obtained from all patients.

Immunohistochemistry(IHC). HC was performed as previously described (5). Briefly, histological sections (thickness, $4 \mu \mathrm{m}$ ) were fixed in $10 \%$ buffered formalin using a polymer peroxidase method (Envision+/HRP; Dako; Agilent Technologies, Inc., Santa Clara, CA, USA) (19). Following deparaffinization with xylene and rehydration using a descending alcohol series, the tissue sections were treated with $0.3 \%$ hydrogen peroxide in methanol for $30 \mathrm{~min}$ at room temperature to block endogenous peroxidase activity. Following rinsing in PBS, the sections were incubated with anti-CDX2 antibody $(1: 1,000$; cat. no. MU392A-UC; clone CDX2-88, Biogenex, San Ramon, CA, USA) and anti-p53 (1:1,000; cat. no. M7000101-2; DO-7, Dako; Agilent Technologies, Inc.) at $4^{\circ} \mathrm{C}$ overnight. An additional wash in PBS was followed by treatment with ready-to-use peroxidase-labeled polymer conjugated to goat anti-rabbit immunoglobulins (cat. no. SM801; ENvision + kit; Dako; Agilent Technologies, Inc.) as the secondary antibody for $30 \mathrm{~min}$ at room temperature. The staining was visualized using diaminobenzidine at room temperature for 5 min, followed by counterstaining with hematoxylin at room temperature for $30 \mathrm{sec}$.

Expression of these proteins was evaluated using optical microscopy (BX43; Olympus Corporation, Tokyo, Japan) and was positive when the nucleus of the cancerous tissue was stained. The staining of each tissue sample was evaluated at $x 40$ or x400 magnification by two investigators, M.S. and K.S. (Fukushima Medical University School of Medicine, Fukushima, Japan), who were blinded to the sample name and the clinical outcomes. The rate of positive stained cancer cells was evaluated in three randomly selected areas (size, $200 \times 200 \mu \mathrm{m})$ from the tumor tissue samples. When the average positive tumor rate was $>10 \%$, the tumor was defined as being positively stained.

Cell culture and transfection. Human gastric carcinoma cell lines AGS, KATOIII, MKN1, MKN45, MKN74, NUGC3, NUGC4 and Okajima used in the present study were originally obtained from the American Type Culture Collection (Manassas, VA, USA). All cells were maintained according to recommended protocols (20) and media with $10 \%$ fetal bovine serum (Thermo Fisher Scientific, Inc.). The monolayer cells were maintained in a $37^{\circ} \mathrm{C}$ incubator with $5 \% \mathrm{CO}_{2}$, observed regularly under a light microscope (magnification, $\mathrm{x} 40$ ) and subcultured when they reached $80-90 \%$ confluency. KATOIII and MKN74 cells were transfected with pre-miR-181b (ID, PM12442) and miR Mimic negative control\#1 (Ambion; Thermo Fisher Scientific, Inc., Waltham, MA, USA, ) using Lipofectamine (RNAiMAX; Invitrogen; Thermo Fisher Scientific, Inc.) according to the manufacturer's instructions. One day prior to transfection, a gastric cancer cell line was seeded at $5 \times 10^{5}$ cells per well on a $6-\mathrm{cm}$ plate. Transfection with a final concentration of $40 \mathrm{nM}$ pre-miR-181b and control was performed when the cell density was $30-50 \%$ on the plates, and the plates were then incubated for $48 \mathrm{~h}$ at $37^{\circ} \mathrm{C}$. Total RNA was extracted $48 \mathrm{~h}$ following transfection using TRIZOL (Invitrogen; Thermo Fisher Scientific, Inc.) according to the manufacturer's instructions. Recombinant human IL-6 (Peprotech, Rocky hill, NJ, USA) was used at $40 \mathrm{ng} / \mathrm{ml}$ for transfection of KATOIII and MKN74 cells.

Reverse transcription polymerase chain reaction ( $R T-P C R)$. Total RNA was isolated from cultured cell lines using TRIzol reagent (Invitrogen; Thermo Fisher Scientific, Inc.) according to the manufacturer's instructions and was quantified by NanoDrop (Thermo Fisher Scientific, Inc.). Subsequently, $5 \mu \mathrm{g}$ total RNA was used for cDNA synthesis using the SuperScript III First Strand cDNA Synthesis kit (Invitrogen; Thermo Fisher Scientific, Inc.) according to the manufacturer's protocol. Conventional PCR was performed using Takara ExTaq DNA polymerase (Takara Bio, Inc., Otsu, Japan). CDX2 and $\beta$-actin mRNA transcripts were amplified using the following primers: CDX2 forward, 5'-CGGCTGGAGCTGGAGAAGG-3' and reverse, 5'-TCA GCCTGGAATTGCTCTGC-3'; $\beta$-actin forward, 5'-GCT CGTCGTCGACAACGGCTC-3' and reverse, 5'-CAAACA TGATCTGGGTCATCTTCTC-3'. The amplification was performed at $94^{\circ} \mathrm{C}$ for 5 min with 30 cycles $(25$ cycles for 
Table I. Characteristics of patients with gastric cancer in the study.

CDX2 expression

\begin{tabular}{|c|c|c|c|c|}
\hline & & & & \\
\hline Parameter & Total, $\mathrm{n}$ & Positive, n (\%) & Negative, n (\%) & $\mathrm{P}$-value \\
\hline $\mathrm{n}$ & 210 & 101 & 109 & \\
\hline Age, year & & & & 0.111 \\
\hline Mean (range) & $64.0(29-87)$ & $65.5(33-87)$ & $62.6(29-87)$ & \\
\hline Gender & & & & 0.006 \\
\hline Male & 149 & $81(80)$ & $68(62)$ & \\
\hline Female & 61 & $20(20)$ & $41(38)$ & \\
\hline Histological type & & & & 0.002 \\
\hline Differentiated & 112 & $65(64)$ & $47(43)$ & \\
\hline Undifferentiated & 98 & $36(36)$ & $62(57)$ & \\
\hline Depth of invasion & & & & $<0.001$ \\
\hline $\mathrm{T} 1$ & 79 & $48(48)$ & $31(28)$ & \\
\hline $\mathrm{T} 2$ & 84 & $43(43)$ & $41(38)$ & \\
\hline $\mathrm{T} 3$ & 46 & $9(9)$ & $37(34)$ & \\
\hline $\mathrm{T} 4$ & 1 & $1(1)$ & 0 & \\
\hline Lymphatic invasion & & & & 0.857 \\
\hline Present & 173 & $84(83)$ & $89(82)$ & \\
\hline Absent & 37 & $17(17)$ & $20(18)$ & \\
\hline Venous invasion & & & & 0.065 \\
\hline Present & 152 & $67(66)$ & $85(78)$ & \\
\hline Absent & 58 & $34(34)$ & $24(22)$ & \\
\hline $\mathrm{LN}$ metastasis & & & & 0.383 \\
\hline Positive & 138 & $63(62)$ & $75(69)$ & \\
\hline Negative & 72 & $38(38)$ & $34(31)$ & \\
\hline TNM stage & & & & $<0.001$ \\
\hline I & 111 & $68(67)$ & $43(39)$ & \\
\hline II & 40 & $16(16)$ & $24(22)$ & \\
\hline III & 59 & $17(17)$ & $42(39)$ & \\
\hline p53 expression & & & & 0.097 \\
\hline Positive & 104 & $56(55)$ & $48(44)$ & \\
\hline Negative & 106 & $44(45)$ & $62(56)$ & \\
\hline
\end{tabular}

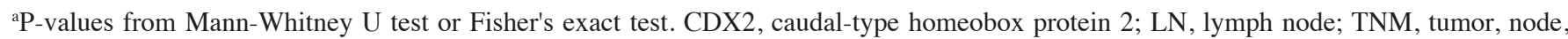
metastasis.

$\beta$-actin) of $94^{\circ} \mathrm{C}$ for $1 \mathrm{~min}, 60^{\circ} \mathrm{C}$ for $30 \mathrm{sec}\left(55^{\circ} \mathrm{C}\right.$ for $\beta$-actin) and $72^{\circ} \mathrm{C}$ for $1 \mathrm{~min}$.

Quantitative reverse transcription polymerase chain reaction $(R T-q P C R)$. RT-qPCR for mRNA and mature microRNA was performed using TaqMan MicroRNA assays (Applied Biosystems; Thermo Fisher Scientific, Inc.) according to manufacturer's instructions with the 7900 HT Fast Real-Time PCR system (Applied Biosystems; Thermo Fisher Scientific, Inc.) at $94^{\circ} \mathrm{C}$ for initial denaturation for $5 \mathrm{~min}$, followed by 35 cycles at $94^{\circ} \mathrm{C}$ for $1 \mathrm{~min}, 55-60^{\circ} \mathrm{C}$ for $45 \mathrm{sec}$ and $72^{\circ} \mathrm{C}$ for $45 \mathrm{sec}(21,22)$. All assays were performed in triplicate and investigators were blinded to the experiment. The TaqMan probes [hsa-miR-181b (ID, 001098), hsa-miR-34a (ID, 00425), CDX2 (ID, Hs01078080_m1), STAT3 (ID, Hs01047580_m1),
RNU66 (ID 001002) and GAPDH (ID, Hs99999905_ml)] were purchased from Applied Biosystems (Thermo Fisher Scientific, Inc.). Relative miRNA or mRNA expression was determined using RNU66 or GAPDH, which were used as a normalization controls, respectively, using the $2^{-\Delta \Delta \mathrm{Cq}}$ method, according to the supplier's protocol (Thermo Fisher Scientific, Inc.) (23).

MicroRNA prediction. A publically available comprehensive database, miRWalk (zmf.umm.uni-heidelberg. de/apps/zmf/mirwalk) was used to identify the miRNAs with the potential to directly suppress CDX2 expression (24). This database provides information on miRNA predicted as well as validated miRNA binding site information on miRNAs for human. 
Table II. Univariate and multivariate Cox regression analysis of CDX2 expression and other parameters for cancer-specific survival.

\begin{tabular}{lcc} 
A, Univariate analysis & & \\
\hline Variable & HR $(95 \%$ CI $)$ & P-value \\
\hline $\begin{array}{l}\text { CDX2 expression } \\
\text { Negative vs. positive }\end{array}$ & $2.60(1.37-5.27)$ & 0.003 \\
$\begin{array}{l}\text { Age, years } \\
>65 \text { vs. } \leq 65\end{array}$ & $1.48(0.81-2.75)$ & 0.206 \\
$\begin{array}{l}\text { Gender } \\
\text { Male vs. female }\end{array}$ & $0.95(0.51-1.89)$ & 0.888 \\
$\begin{array}{l}\text { Histological type } \\
\text { Undifferentiated }\end{array}$ & & \\
$\quad$ vs. differentiated & $1.07(0.59-1.96)$ & 0.814 \\
$\begin{array}{l}\text { Stage } \\
\text { III vs. I \& II }\end{array}$ & $6.50(3.52-12.50)$ & $<0.001$ \\
\hline
\end{tabular}

$\mathrm{B}$, Multivariate analysis

\begin{tabular}{lll}
\hline Variable & HR $(95 \% \mathrm{CI})$ & P-value \\
\hline
\end{tabular}

CDX2 expression

Negative vs. positive

$2.10(1.05-4.41)$

0.035

Age, years

$>65$ vs. $\leq 65$

$2.11(1.14-4.00)$

0.018

Gender

Male vs. female

$0.99(0.50-2.02)$

0.967

Histological type

Undifferentiated vs.

differentiated

$0.69(0.36-1.32)$

0.266

Stage

III vs. I and II

$7.10(3.72-14.08)$

$<0.001$

CDX2, caudal-type homeobox protein 2 ; HR, hazard ratio; CI, confidence interval.

Statistical analysis. The patients were divided into high or low expression groups based on the intensity of immunostaining for CDX2 and p53, according to previously described criteria (5). Univariate and multivariate Cox regression was used to evaluate the associations between clinical factors and cancer-specific survival and overall survival in JMP 10 (www .jmp.com; SAS Institute, NC, USA). For all analyses, age was treated as a categorical variable as $>65$ or $<65$ years. Histology was categorized as undifferentiated vs. differentiated. TNM staging $(17,18)$ was categorized as stage I vs. stage II/III. For multivariable Cox regression models, all variables were included with cancer-specific survival. Kaplan-Meier analysis was performed using Graphpad Prism (v.5.0; GraphPad Software, Inc., La Jolla, CA, USA). Quantitation of relative expression of microRNA was calculated with RQ manager 1.2 (Applied Biosystems; Thermo Fisher Scientific, Inc.).

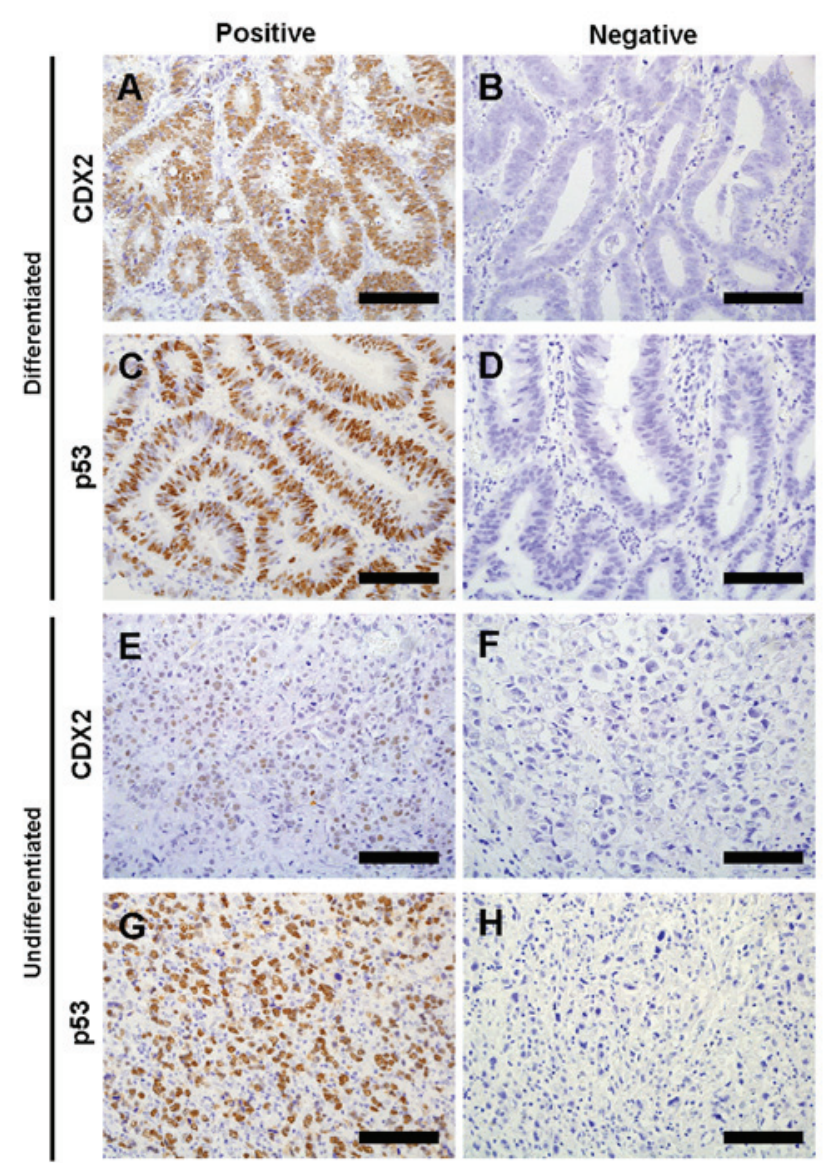

Figure 1. Representative images of immunohistochemical staining of CDX2 and 553 in gastric cancer tissues. (A) Positive and (B) negative CDX2 staining in differentiated gastric cancer tissues. (C) Positive and (D) negative p53 staining in differentiated gastric cancer tissues. (E) Positive and (F) negative CDX2 staining in undifferentiated gastric cancer tissues. (G) Positive and $(\mathrm{H})$ negative $\mathrm{p} 53$ staining in undifferentiated gastric cancer tissues. Scale bar, $100 \mu \mathrm{m}$. CDX2, caudal-type homeobox protein 2 .

Differences in mRNA and microRNA expression between control cells and treated cells were analyzed by unpaired t-test (GraphPad Software, Inc.). All data are expressed as the mean \pm standard deviation. $\mathrm{P}<0.05$ was considered to indicate a statistically significant difference.

\section{Results}

CDX2 expression is associated with clinicopathological factors. The authors of the present study evaluated CDX2 and p53 expression in 210 gastric cancer tumor samples by IHC (Fig. 1). Characteristics of these patients subjected to CDX2 expression are summarized in Table I. CDX2 expression was positive in 101 cases $(48.1 \%)$, whereas negative in 109 cases $(51.9 \%)$. The percentage of negative CDX2 expression was significantly higher in females compared with males $(\mathrm{P}=0.006)$ and in undifferentiated histological type compared with differentiated type $(\mathrm{P}=0.002)$. In addition, there was a statistically significant inverse association between CDX2 expression and depth of invasion $(\mathrm{P}<0.001)$ or stage $(\mathrm{P}<0.001)$, respectively.

CDX2 is associated with poor prognosis in gastric cancer. In order to investigate whether $\mathrm{CDX} 2$ is a potential 
Table III. Univariate analysis of $\mathrm{CDX} 2$ expression and parameters for overall survival.

\begin{tabular}{lcc}
\hline Variable & HR $(95 \%$ CI $)$ & P-value \\
\hline $\begin{array}{l}\text { CDX2 expression } \\
\text { Negative vs. positive }\end{array}$ & $1.47(0.92-2.40)$ & 0.107 \\
$\begin{array}{l}\text { Age, year } \\
>65 \text { vs. } \leq 65\end{array}$ & $1.91(1.18-3.13)$ & 0.008 \\
$\begin{array}{l}\text { Gender } \\
\text { Male vs. female }\end{array}$ & $1.43(0.84-2.59)$ & 0.191 \\
$\begin{array}{l}\text { Histological type } \\
\text { Undifferentiated vs. }\end{array}$ & $0.92(0.57-1.47)$ & 0.731 \\
$\quad$ differentiated & & \\
$\begin{array}{l}\text { Stage } \\
\text { III vs. I and II }\end{array}$ & $3.20(2.00-5.12)$ & $<0.001$ \\
\hline
\end{tabular}

CDX2, caudal-type homeobox protein 2 ; HR, hazard ratio; CI, confidence interval.

prognostic biomarker, Cox regression analysis was performed. Cancer-specific survival and overall survival times were used as an endpoint for the present cohort. Negative expression of CDX2 was significantly associated with poor cancer-specific survival (hazard ratio $[\mathrm{HR}]=2.60,95 \%$ confidence interval $[C I]=1.37-5.2$; Table II $)$ but not overall survival $(\mathrm{HR}=1.47,95 \%$ $\mathrm{CI}=0.92-2.40$; Table III). Multivariate Cox regression analysis demonstrated that CDX2 expression was associated with poor cancer-specific survival in the present cohort independent of staging (HR=2.10, 95\% CI=1.05-4.41; Table II).

Kaplan-Meier analysis further demonstrated that patients with decreased CDX2 expression had significantly poorer cancer-specific survival outcome $(\mathrm{P}=0.004)$ but not overall survival $(\mathrm{P}=0.109)$ in the present cohort (Fig. 2). The significant associations between CDX2 expression and cancer-specific survival suggest that CDX2 expression may be a useful prognostic biomarker for gastric cancer.

CDX2 expression is dependent on $p 53$ expression and histological differentiation. The rate of positive p53 expression of was less frequent in gastric cancer tissues with negative CDX2 expression compared with tissues with positive CDX2 expression $(\mathrm{P}=0.097$; Table I). When the authors focused on CDX2-negative gastric cancer tissues, it was identified that cases with p53 positive expression were significantly less frequent in undifferentiated type compared with differentiated type $(\mathrm{P}=0.021$; Table IV). These results indicated that the TP53 gene was less frequently mutated in undifferentiated gastric cancer with negative CDX2 expression compared with differentiated gastric cancer.

CDX2 is suppressed during inflammation-associated carcinogenesis. Recent studies have revealed that gene expression can be specifically controlled by miRNAs. Therefore, the authors of the present study have investigated to find out which miRNA has the potential to directly suppress CDX2 expression. Based on the published data (15) and miRwalk (24), which consists
Table IV.Evaluation of IHC for CDX2 and p53 in differentiated and undifferentiated gastric cancer.

A, Negative CDX2 expression

\begin{tabular}{lccc}
\hline Expression & Differentiated & Undifferentiated & P-value $^{\mathrm{a}}$ \\
\hline $\begin{array}{l}\text { Positive p53 } \\
\text { expression }\end{array}$ & 27 & 21 & 0.021 \\
$\begin{array}{l}\text { Negative p53 } \\
\text { expression }\end{array}$ & 21 & 41 & \\
\hline
\end{tabular}

B, Positive CDX2 expression

\begin{tabular}{lccc}
\hline Expression & Differentiated & Undifferentiated & P-value $^{\mathrm{a}}$ \\
\hline $\begin{array}{l}\text { Positive p53 } \\
\text { expression }\end{array}$ & 37 & 19 & 0.678 \\
$\begin{array}{l}\text { Negative p53 } \\
\text { expression }\end{array}$ & 27 & 17 & \\
\hline
\end{tabular}

aP value from Fisher's exact test. CDX2, caudal-type homeobox protein 2 .

of 8 established miRNA-target prediction programs, the authors of the present study selected miR-181b, which is part of the IL-6/STAT3 signaling pathway. To examine whether miR-181b may directly suppress CDX2 expression, the authors examined the level of CDX2 expression in gastric cancer cell lines and selected KATOIII (p53-null) and MKN74 (p53-wild type) cells for further experiments (Fig. 3A). Overexpression of mature miR-181b by pre-miR-181b transfection suppressed CDX2 mRNA expression in KATOIII and MKN74 gastric cancer cell lines (Fig. 3B). Compared with the control cells, CDX2 was 0.5- and 0.6-fold lower in both cell lines that overexpress miR-181b, respectively, suggesting that miR-181b may directly suppress CDX2 expression in vitro.

Next, overexpression of IL-6 by transfection of recombinant IL-6 induced STAT3 mRNA expression in KATOIII and MKN74 cancer cell lines (Fig. 3C). However, while induction of miR-181b and suppression of miR-34b expression by overexpression of IL-6 were observed in p53 wild-type MKN74 cells, those were not observed in p53 deleted KATOIII cells (Fig. 3D). These results suggest that activation of the IL-6/STAT3 signaling pathway suppresses CDX2 expression by inducing miR-181b and also may suppress $\mathrm{p} 53$ and miR-34a expression in tumor with wild-type p53 (Fig. 3E).

\section{Discussion}

In the present study, the authors have demonstrated that the association of decreased CDX2 expression with poorer gastric cancer prognosis was significant. According to a previous meta-analysis of CDX2 expression in gastric cancer, which analyzed a combination of 4 different cohorts containing 475 patients, CDX2 was identified as a prognostic factor in gastric cancer (25). Although whether CDX2 may be associated with patient outcome remains controversial, to the best 
A

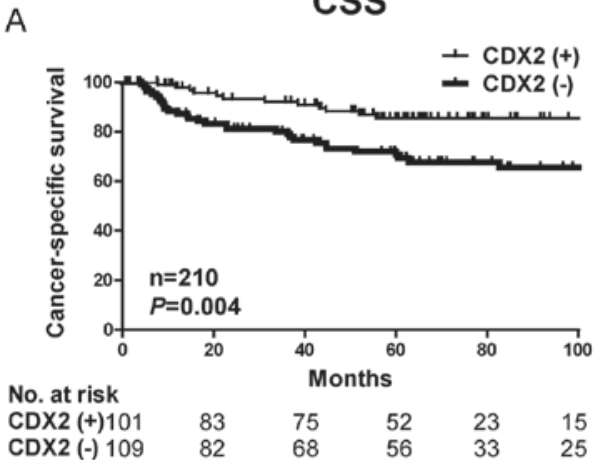

B

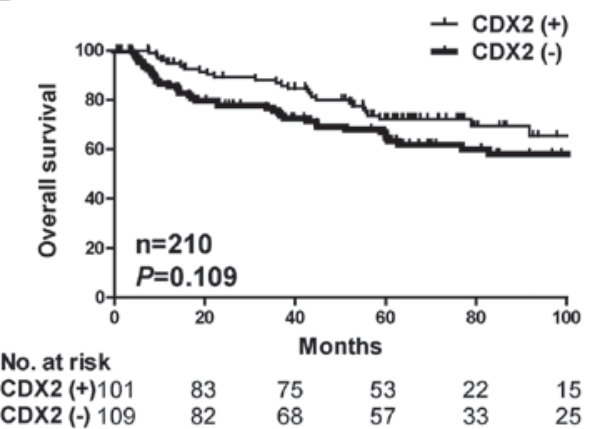

Figure 2. Kaplan-Meier survival analysis of cancer specific and overall survival with all cases stratified by CDX2 tumor expression. (A) Patients with negative CDX2 expression had the poorest outcome for cancer specific survival. $\mathrm{P}=0.004$. (B) However, the association between negative CDX2 expression and overall survival time was not significant. $\mathrm{P}=0.109$. CDX2, caudal-type homeobox protein 2; CSS, cancer-specific survival; OS, overall survival.

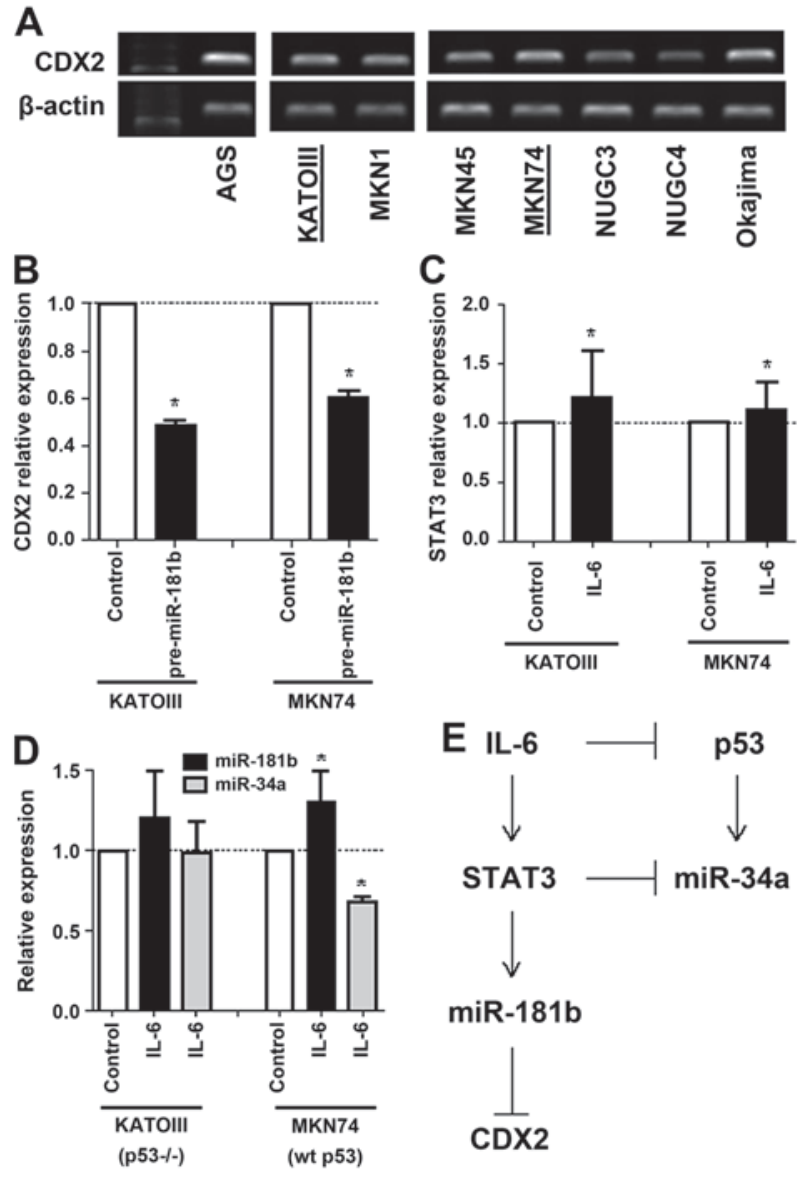

Figure 3. Functional relationship between IL-6/STAT3 and p53 signaling pathways including a mechanism for miRNA-mediated CDX2 suppression. (A) RT-qPCR analysis of CDX2 expression in 8 gastric cancer cell lines. (B) RT-qPCR analysis of CDX2 mRNA expression. CDX2 was suppressed by pre-miR-181b transfection in KATOIII and MKN74 cells. ${ }^{*} \mathrm{P}<0.05$. (C) RT-qPCR analysis of STAT3 mRNA expression. STAT3 expression was increased by IL-6 recombinant transfection in KATOIII and MKN74 cells. ${ }^{*} \mathrm{P}<0.05$. (D) RT-qPCR analysis of miR-181b and miR-34a expression. miR-181b expression was increased, and miR-34a expression was suppressed by IL-6 recombinant transfection in MKN74 cells. ${ }^{*} \mathrm{P}<0.05$. (E) Schematic representation of CDX2 suppression and proposed IL-6/STAT3 and p53 signaling pathways including miR-181b and miR-34a. CDX2, caudal-type homeobox protein 2; IL, interleukin; miR, microRNA; RT-qPCR, quantitative reverse transcription polymerase chain reaction; STAT3, signal transducer and activator of transcription 3; WT, wild-type. our knowledge the present study is the largest study to date with 210 cases, which provides additional evidence that CDX2 is an important prognostic biomarker for gastric cancer.

A previous report demonstrated that nuclear staining of CDX2 in IHC examination was a robust biomarker for predicting prognosis in gastric cancer, whereas cytoplasmic staining of CDX2 was not (5). Although the clinical significance of nuclear and cytoplasmic staining has not fully understood, previous studies by the authors (5) and the present study also used nuclear staining of CDX2 for analysis and confirmed positive association with patient outcome but not cytoplasmic staining (data not shown). Consistent with previous reports $(5,25)$, in the present study decreased CDX2 expression was associated with a higher proportion of cases with poorly differentiated histological type. The authors also performed IHC analysis of p53 and revealed that there was a significant low frequency of positive p53 expression in gastric cancer tissues that are negative for CDX2 expression and undifferentiated. This result suggests that gastric cancer with negative CDX2 expression occurs when there is a low frequency of TP53 mutation or high frequency of p53 inactivation.

STAT3 is a downstream effector of IL-6 and form an inflammatory positive feedback loop with miR-181b (14). The miR-181 family exhibits cancer-specific expression patterns, and miR-181b is upregulated in various malignant neoplasms, including breast, pancreas, prostate, esophagus and gastric cancer (15,26-29). In gastric cancer cell lines, miR-181b significantly increased cell proliferation, migration and invasion (30). The present study revealed that miR-181b directly regulates CDX2 expression in vitro and thus that miR-181b has a central role in inflammation-associated carcinogenesis. It was also found that miR-34a is suppressed by activation of the IL-6/STAT3 signaling pathway. Since miR-34a is induced by activation of $\mathrm{p} 53$, suppression of miR-34a may frequently occur in tumor with wild-type p53. Notably, a previous report demonstrated that the IL-6/STAT3 signaling pathway was also able to downregulate p53 expression (31). Considering the IHC results in the present study, the activation of the IL-6/STAT3 signaling pathway may contribute to gastric carcinogenesis via suppression of CDX2 and inactivation of p53, resulting in a poor prognostic outcome. 
The present study has several limitations. While the present study has attempted to elucidate a functional relationship between inflammation and gastric carcinogenesis in vitro, further studies to investigate the interactions between IL-6/STAT3 and p53 signaling pathways are required. The present study has only suggested that CDX2 expression is associated with p53 inactivation. Additionally, it was not possible to collect patient history of $H$. pylori infection. $H$. pylori infection is a sign for chronic inflammation status, which is the main risk factor for gastric cancer development. Therefore, this risk factor was not examined. Previously, it was shown that STAT3 can be activated by H. pylori infection (32), therefore further studies that take this factor into account are required.

\section{Acknowledgements}

The present study was supported by JSPS KAKENHI (grant no. 24791439).

\section{References}

1. Jemal A, Bray F, Center MM, Ferlay J, Ward E and Forman D: Global cancer statistics. CA Cancer J Clin 61: 69-90, 2011.

2. Torre LA, Sauer AM, Chen MS Jr, Kagawa-Singer M, Jemal A and Siegel RL: Cancer statistics for Asian Americans, Native Hawaiians, and Pacific Islanders, 2016: Converging incidence in males and females. CA Cancer J Clin 66: 182-202, 2016.

3. Polk DB and Peek RM Jr: Helicobacter pylori: Gastric cancer and beyond. Nat Rev Cancer 10: 403-414, 2010.

4. Schetter AJ, Heegaard NH and Harris CC: Inflammation and cancer: Interweaving microRNA, free radical, cytokine and p53 pathways. Carcinogenesis 31: 37-49, 2010.

5. Okayama H, Kumamoto K, Saitou K, Hayase S, Kofunato Y Sato Y, Miyamoto K, Nakamura I, Ohki S, Sekikawa K and Takenoshita S: CD44v6, MMP-7 and nuclear Cdx2 are significant biomarkers for prediction of lymph node metastasis in primary gastric cancer. Oncol Rep 22: 745-755, 2009.

6. Liu Q, Teh M, Ito K, Shah N, Ito Y and Yeoh KG: CDX2 expression is progressively decreased in human gastric intestinal metaplasia, dysplasia and cancer. Mod Pathol 20: 1286-1297, 2007.

7. Bai Z, Ye Y, Chen D, Shen D, Xu F, Cui Z and Wang S: Homeoprotein $\mathrm{Cdx} 2$ and nuclear PTEN expression profiles are related to gastric cancer prognosis. APMIS 115: 1383-1390, 2007

8. Fan Z, Li J, Dong B and Huang X: Expression of Cdx2 and hepatocyte antigen in gastric carcinoma: Correlation with histologic type and implications for prognosis. Clin Cancer Res 11: 6162-6170, 2005

9. Ge J, Chen Z, Wu S, Yuan W, Hu B and Chen Z: A clinicopathological study on the expression of cadherin-17 and caudal-related homeobox transcription factor (CDX2) in human gastric carcinoma. Clin Oncol (R Coll Radiol) 20: 275-283, 2008.

10. Zhang X, Tsukamoto T, Mizoshita T, Ban H, Suzuki H, Toyoda T and Tatematsu M: Expression of osteopontin and CDX2: Indications of phenotypes and prognosis in advanced gastric cancer. Oncol Rep 21: 609-613, 2009.

11. Silberg DG, Sullivan J, Kang E, Swain GP, Moffett J, Sund NJ, Sackett SD and Kaestner KH: Cdx2 ectopic expression induces gastric intestinal metaplasia in transgenic mice. Gastroenterology 122: 689-696, 2002.

12. Mutoh H, Sakurai S, Satoh K, Tamada K, Kita H, Osawa H, Tomiyama T, Sato Y, Yamamoto H, Isoda N, et al: Development of gastric carcinoma from intestinal metaplasia in Cdx2-transgenic mice. Cancer Res 64: 7740-7747, 2004.

13. Huntzinger E and Izaurralde E: Gene silencing by microRNAs: Contributions of translational repression and mRNA decay. Nat Rev Genet 12: 99-110, 2011.

14. Iliopoulos D, Jaeger SA, Hirsch HA, Bulyk ML and Struhl K: STAT3 activation of miR-21 and miR-181b-1 via PTEN and CYLD are part of the epigenetic switch linking inflammation to cancer. Mol Cell 39: 493-506, 2010.
15. Ji J, Yamashita T, Budhu A, Forgues M, Jia HL, Li C, Deng C, Wauthier E, Reid LM, Ye QH, et al: Identification of microRNA-181 by genome-wide screening as a critical player in EpCAM-positive hepatic cancer stem cells. Hepatology 50: 472-480, 2009.

16. Rokavec M, Öner MG, Li H, Jackstadt R, Jiang L, Lodygin D, Kaller M, Horst D, Ziegler PK, Schwitalla S, et al: IL-6R/STAT3/miR-34a feedback loop promotes EMT-mediated colorectal cancer invasion and metastasis. J Clin Invest 124: 1853-1867, 2014.

17. Sobin LH and Compton CC: TNM seventh edition: What's new, what's changed: Communication from the international union against cancer and the american joint committee on cancer. Cancer 116: 5336-5339, 2010.

18. Sobin LH, Gospodarowicz MK, Wittekind $\mathrm{CH}$; International Union against Cancer(UICC): TNM Classification of Malignant Tumors 7th edition. Oxford, UK, Wiley-Blackwell, 2009.

19. Tachibana K, Saito M, Imai JI, Ito E, Yanagisawa Y, Honma R, Saito K, Ando J, Momma T, Ohki S, et al: Clinicopathological examination of dipeptidase 1 expression in colorectal cancer. Biomed Rep 6: 423-428, 2017.

20. Bai Y, Akiyama Y, Nagasaki H, Yagi OK, Kikuchi Y, Saito N, Takeshita K, Iwai T and Yuasa Y: Distinct expression of CDX2 and GATA4/5, development-related genes, in human gastric cancer cell lines. Mol Carcinog 28: 184-188, 2000.

21. Saito M, Schetter AJ, Mollerup S, Kohno T, Skaug V, Bowman ED, Mathé EA, Takenoshita S, Yokota J, Haugen A and Harris CC: The association of microRNA expression with prognosis and progression in early-stage, non-small cell lung adenocarcinoma: A retrospective analysis of three cohorts. Clin Cancer Res 17: 1875-1882, 2011

22. Saito M, Shiraishi K, Matsumoto K, Schetter AJ, Ogata-Kawata H, Tsuchiya N, Kunitoh H, Nokihara H, Watanabe S, Tsuta K, et al: A three-microRNA signature predicts responses to platinum-based doublet chemotherapy in patients with lung adenocarcinoma. Clin Cancer Res 20: 4784-4793, 2014.

23. Livak KJ and Schmittgen TD: Analysis of relative gene expression data using real-time quantitative PCR and the 2(-Delta Delta C(T)) method. Methods 25: 402-408, 2001.

24. Dweep H and Gretz N: miRWalk2.0: A comprehensive atlas of microRNA-target interactions. Nat Methods 12: 697, 2015.

25. Wang XT, Wei WY, Kong FB, Lian C, Luo W, Xiao Q and Xie YB: Prognostic significance of $\mathrm{Cdx} 2$ immunohistochemical expression in gastric cancer: A meta-analysis of published literatures. J Exp Clin Cancer Res 31: 98, 2012

26. Wang J, Sai K, Chen FR and Chen ZP: miR-181b modulates glioma cell sensitivity to temozolomide by targeting MEK1. Cancer Chemother Pharmacol 72: 147-158, 2013.

27. Wang B, Hsu SH, Majumder S, Kutay H, Huang W, Jacob ST and Ghoshal K: TGFbeta-mediated upregulation of hepatic miR-181b promotes hepatocarcinogenesis by targeting TIMP3. Oncogene 29: 1787-1797, 2010.

28. Zhao Y, Schetter AJ, Yang GB, Nguyen G, Mathé EA, Li P, Cai H, Yu L, Liu F, Hang D, et al: microRNA and inflammatory gene expression as prognostic marker for overall survival in esophageal squamous cell carcinoma. Int J Cancer 132: 2901-2909, 2013.

29. Volinia S, Calin GA, Liu CG, Ambs S, Cimmino A, Petrocca F, Visone R, Iorio M, Roldo C, Ferracin M, et al: A microRNA expression signature of human solid tumors defines cancer gene targets. Proc Natl Acad Sci USA 103: 2257-2261, 2006.

30. Guo JX, Tao QS, Lou PR, Chen XC, Chen J and Yuan GB: miR-181b as a potential molecular target for anticancer therapy of gastric neoplasms. Asian Pac J Cancer Prev 13: 2263-2267, 2012.

31. Brighenti E, Calabrese C, Liguori G, Giannone FA, Trerè D, Montanaro L and Derenzini M: Interleukin 6 downregulates p53 expression and activity by stimulating ribosome biogenesis: A new pathway connecting inflammation to cancer. Oncogene 33: 4396-4406, 2014.

32. Giraud AS, Menheniott TR and Judd LM: Targeting STAT3 in gastric cancer. Expert Opin Ther Targets 16: 889-901, 2012. 